\title{
Hartmann's mountain zebra resource selection and movement behavior within a large unprotected landscape in northwest Namibia
}

\author{
Jeff R. Muntifering ${ }^{1, *}$, Mark A. Ditmer ${ }^{1,2}$, Seth Stapleton $^{1,2}$, Robin Naidoo ${ }^{3}$, \\ Tara H. Harris ${ }^{1,2}$ \\ ${ }^{1}$ Conservation Department, Minnesota Zoo, 13000 Zoo Boulevard, Apple Valley, MN 55124, USA \\ ${ }^{2}$ Department of Fisheries, Wildlife and Conservation Biology, University of Minnesota, St. Paul, MN 55108, USA \\ ${ }^{3}$ World Wildlife Fund, 1250 24th Street NW, Washington, DC 20090, USA
}

\begin{abstract}
Expanding human populations, combined with an increasingly variable climate, present challenges to the conservation of wide-ranging wildlife species, particularly for populations that persist in human-dominated landscapes. Although the movements and space use of many equid species have been well studied, comparable research of the Hartmann's mountain zebra (HMZ) Equus zebra hartmannae, which primarily inhabits communal and commercial farming areas of Namibia, has been scarce and may limit conservation effectiveness. Here, we investigated the environmental and anthropogenic factors influencing HMZ movements and resource use across a large area of their range in northwestern Namibia. We deployed 6 GPS collars on HMZ during 2011 to 2013 and used integrated step selection functions to quantify HMZ movements and space use. HMZ movements averaged $\sim 5 \mathrm{~km} \mathrm{~d}^{-1}$, and mean seasonal home range sizes were 681 and $256 \mathrm{~km}^{2}$ in the wet and dry season, respectively. HMZ selected for areas with high normalized difference vegetation index values (used as a proxy for primary production), particularly during the dry season, while avoiding areas further from water and closer to human settlements, although the effect was less apparent during the rainy season. Movement rates increased when HMZ crossed roads and were closer to roadways, but rates were not impacted by proximity to human activities. These results provide insights toward mitigating human-HMZ conflict. We highlight the difficulty a changing and less predictable climate creates for grazing species living in arid regions, as they must expend more energy and navigate dangers of a growing human footprint to seek out valuable but ephemeral forage.
\end{abstract}

KEY WORDS: Hartmann's mountain zebra - Habitat · Resource selection · Integrated step selection function $\cdot$ Movement $\cdot$ Seasonality $\cdot$ Namibia

\section{INTRODUCTION}

Understanding the environmental and anthropogenic factors that influence animal movements and resource use is fundamental for effective conservation planning (Boyce 2006, Naidoo et al. 2014, Ripple et al. 2016). It can be especially important for threatened species that move considerable distances

\footnotetext{
${ }^{*}$ Corresponding author: jmuntif@gmail.com
}

across seasons, particularly outside of protected areas, and must seek limited or variable resources (Poor et al. 2012, Ripple et al. 2017, Purdon et al. 2018). Examining fine-scale space and habitat-use patterns of individual animals from focal species can help determine what landscape components are essential for their future conservation, particularly as landscapes change due to anthropogenic transforma-

() The authors 2019. Open Access under Creative Commons by Attribution Licence. Use, distribution and reproduction are unrestricted. Authors and original publication must be credited. 
tion and/or changing climates (Wasserman et al. 2012, Zeller et al. 2012)

Wild and feral equids inhabit diverse grassland, shrubland, and woodland environments around the world and frequently display seasonal changes in home range dimensions or use in response to shifts in water and vegetation availability (Bartlam-Brooks et al. 2013, Naidoo et al. 2014, Schoenecker et al. 2016). Of the 7 extant species of wild equids recognized by the IUCN Equid Specialist Group, all but the kiang Equus kiang are considered threatened (Vulnerable, Endangered, or Critically Endangered) or Near Threatened (IUCN 2017). Most of these equids have experienced moderate to severe population and/or range declines during the past 50 to $100 \mathrm{yr}$ as people and livestock have increasingly competed with them for land and other resources, and as people have targeted them for hunting - especially outside of protected areas (Moehlman et al. 2016, Parker et al. 2017, O'Brien et al. 2018).

Considered vulnerable to extinction (Gosling et al. 2018), the mountain zebra E. zebra is a wild equid native to southern Africa. Most nontaxonomic research to date has focused on the Cape mountain zebra E. $z$. zebra subspecies of South Africa, including studies of behavior, ecology, and demography (Penzhorn 1982, 1988, Lloyd \& Rasa 1989, Penzhorn \& Novellie 1991, Rasa \& Lloyd 1994, Smith et al. 2007), effects of habitat selection (Weel et al. 2015, Lea et al. 2016, 2018), and management (Watson et al. 2005, Watson \& Chadwick 2007, Novellie et al. 2017) as well as disease and parasites (Krecek et al. 1994). Far less is known about the Hartmann's mountain zebra E. $z$. hartmannae, the only other subspecies.

Classified as Vulnerable by the IUCN, Hartmann's mountain zebra (hereafter HMZ) are distributed primarily along the western escarpment of Namibia, stretching slightly into northwestern South Africa and southwestern Angola (Gosling et al. 2018). The largest population of free-roaming (i.e. not on privately owned and fenced commercial farms) HMZ exists in northwestern Namibia, primarily on arid unprotected communal lands. The start of the annual summer rains, usually in November or December, triggers a seasonal migration of large numbers of HMZ (Joubert 1972). Anecdotal evidence suggests these seasonal movements can sometimes span hundreds of kilometers, and previous aerial and ground surveys from this region suggest that ungulates undertake seasonal movements in search of grazing (i.e. green vegetation flushes) and water resources, though data on HMZ were very limited (Leggett et al. 2004). Since HMZ are presumed to move over very large distances in response to spatial and temporal variation in rainfall and primary production, very large areas that are connected and support suitable habitat are needed if viable populations are to survive. Recent climate projections suggest Namibia's northwest will become hotter and drier (Maure et al. 2018), potentially placing additional stress on HMZ, both directly and indirectly through increased competition with pastoralists for grazing. Thus, understanding how individuals within this key population use the large formally unprotected landscape of northwestern Namibia, especially as seasonal resource availability changes, is essential for effective conservation.

We investigated seasonal changes in movement patterns as well as the environmental and anthropogenic factors influencing wild HMZ movements and resource selection in unprotected areas of northwest Namibia. We hypothesized that mountain zebra will (1) seasonally move towards and be located in areas with the greenest vegetation, (2) restrict their movements to areas relatively close to water sources, (3) avoid areas of heavy use by people and/or livestock, (4) have movements restricted by natural topographic features, and (5) alter their movement and resource selection patterns when near or crossing anthropogenic features such as roadways as they seek out forage. To test these hypotheses, we analyzed the movements and resource use of GPS-collared HMZ using integrated step selection functions (SSFs), which allow for the quantification of factors that alter animal movement and resource selection patterns (Avgar et al. 2016). Our overall aim was to identify the primary factors that drive HMZ space use throughout the year in a landscape with an increasing human influence and a changing climate.

\section{MATERIALS AND METHODS}

\subsection{Study site}

Our study area encompassed $14227 \mathrm{~km}^{2}$ of communal land within the northwestern HMZ subpopulation's range in the Kunene region of Namibia; $7634 \mathrm{~km}^{2}$ is categorized as communal conservancy land, and $6593 \mathrm{~km}^{2}$ is classified as state-administered concession areas. The area averages 50 to $300 \mathrm{~mm}$ of rainfall per annum, which primarily falls during the rainy season (November-April), across an elevation range from 242 to $1654 \mathrm{~m}$ on the largest flat-topped Etendeka mountains (Mendelsohn et al. 2003, Muntifering et al. 2008). Geologically, the landscape is bro- 
ken into a 132 million year old basalt deposit covering $\sim 40 \%$ of the study area and granite hills which support a relatively diverse assemblage of shrubs and annual and perennial grasses. The land is bisected by dry drainages dominated by mopane Colophospermum mopane and camelthorn trees Vachellia erioloba interspersed with natural springs (Jacobson \& Jacobson 1995). In addition to the near-endemic $\mathrm{HMZ}$, other native ungulate species that may compete with $\mathrm{HMZ}$ for resources include springbok Antidorcas marsupialis and oryx Oryx gazella. Dominant predators that are known to predate on HMZ are lion Pathera leo, leopard Panthera pardus, cheetah Acinonyx jubatus, and spotted hyaena Crocuta crocuta.

Human habitation and activity in the concession areas are limited to $\sim 100$ permanent staff residing at 5 permanent tourism camps. About 6700 people reside within the conservancy landscapes surrounding the concession areas, including Sesfontein, Anabeb, Omatendeka, and Ehirovipuka conservancies, scattered across $~ 80$ small settlements (NACSO 2014). The dominant livelihood practice among these communities is semi-nomadic pastoral farming. Small herds of livestock including cattle, goats, and sheep are maintained across the landscape and are managed locally from each settlement (Muntifering et al. 2008). HMZ are utilized both nonconsumptively as a major attraction for Namibia's popular photographic safari tourism industry (NACSO 2014) and consumptively, with an average of $\sim 3500$ hunted annually between 2008 and 2012 for commercial use of their meat and skins (Gosling et al. 2018).

\subsubsection{HMZ capture}

We captured and fitted satellite tracking collars to 6 adult HMZ. In November 2011, 4 HMZ were captured within the Palmwag Concession (1953' 12" S, $\left.13^{\circ} 56^{\prime} 13^{\prime \prime} \mathrm{E}\right)$ and 1 in the neighboring Etendeka Concession $\left(19^{\circ} 45^{\prime} 33^{\prime \prime} \mathrm{S}, 13^{\circ} 57^{\prime} 42^{\prime \prime} \mathrm{E}\right)$. Animals were darted from a helicopter by a certified veterinarian and were handled according to the protocols approved under research permit 1408/2009 from the Ministry of Environment and Tourism in Namibia. We outfitted these individuals (1 male stallion, 1 bachelor male, and 3 mares, all from different independent groups) with GPS satellite collars (Africa Wildlife Tracking) and monitored their movements between November 2011 and March 2013. Collars were programmed to attempt to collect a location every $4 \mathrm{~h}$. An additional bachelor male was captured and collared using the same methods as above within
Etendeka Concession in July 2010 and was monitored until September 2010 using a GPS-UHF collar programmed to collect a location every half hour.

\subsubsection{Spatial summary statistics}

We calculated summary statistics of zebra movement to highlight broad-scale differences among individuals and seasons and for comparative purposes with previous zebra studies using the program R (R Development Core Team 2015). Metrics included (1) daily movement distance, (2) net squared displacement, (3) home range size using both the 95\% minimum convex polygon and kernel density estimates (KDEs; package adehabitatHR) (Calenge 2006), using an ad hoc method for choosing the smoothing parameter), (4) estimates of kernel density home range overlap (basic proportions using function kerneloverlaphr), (5) Euclidean distance (note: all distance estimates in our analyses were Euclidean) to natural water sources $(\mathrm{km}$; see WaterDist, Section 2.2.2), and (6) elevation ranges ( $m$; see Elev, Section 2.2.2). We calculated nonparametric bootstrapped confidence intervals based on 10000 samples from individual zebra sample mean values with the package boot (Canty \& Ripley 2017) using the adjusted bootstrap percentile method. For any statistic that compared values between seasons, we could only use 5 of the 6 zebra because 1 zebra only collected GPS locations during a single dry season.

\subsubsection{Integrated SSFS}

SSFs estimate resource selection at the data's finest spatiotemporal scales by comparing animal locations, and their associated movement steps which connect each set of sequential locations, to randomized movements that can be drawn from empirical distributions of the animal movements (Thurfjell et al. 2014). Because the random locations incorporate the movement characteristics of the individual animal, they provide a more realistic comparison, relative to traditional resource selection functions, between actual resource use and what was available at the same moment in time given biologically feasible movement distances. Integrated SSFs (iSSFs) not only estimate resource use but can also provide insight into how landscape features and resources shape animal movement during the process of resource selection by including movement characteristics in the same model (Avgar et al. 2016). 
Using the package amt (Signer 2018, Signer et al. 2019), we regularized timesteps from the GPS locations of the 6 collared zebra. We created movement bursts, which we defined as groups of GPS locations that were no more than $4 \mathrm{~h}$ apart. Using these bursts, we calculated step length (straight-line distance between starting GPS location and the terminal location of each step) and turning angles (derived from the headings of 2 sequential steps) associated with each movement step. Any movement burst without adequate locations to calculate turning angles was removed from the dataset, yielding a total of 10835 used zebra steps for analyses. We then generated 15 random steps per used step. A large number of random steps is not needed for estimating SSFs (Northrup et al. 2013), so we chose a value similar to other studies with a similar fix frequency (Thurfjell et al. 2014). To generate random steps, we fit gamma distributions to each individual's step length values and a von Mises distribution to individual turn angles. We then used these distributions to draw the random movement steps, with their associated step lengths and turn angles, based on the derived terminal coordinate values.

\subsection{Model covariates}

We calculated the log-transformed distance of step length (StepLen) and the cosine of turning angle (TurnAng). By taking the cosine of the turning angle, values of TurnAng take values between -1 and 1 , where -1 indicates a complete $180^{\circ}$ turn from the previous heading and 1 represents moving in the same direction as the previous heading (Benhamou 2006). In addition to step lengths and turn angles, we calculated covariate values of both used and random steps for temporal, natural resource, and human factors known or suspected to be important predictors of HMZ habitat selection or movement.

\subsubsection{Temporal patterns}

To assess seasonal trends in movement and selection, we assigned all timestamps associated with the terminal location of each step a season (rainy [November-April] or dry [May-October]) based on the precipitation patterns of this region of Namibia. We used the function sunpos in the package maptools (Bivand \& Lewin-Koh 2017) to assign the timestamp of each step's terminal location a day period (DayPeriod) based on the elevation of the sun (day:
$>20$, night: $<-20$, crepuscular: 20 to -20 ; location was based on coordinates of terminal GPS location).

\subsubsection{Natural resources}

For each GPS location, we included terrain covariates based on elevation ( $\mathrm{m}$; Elev) and slope $\left({ }^{\circ}\right.$; Slope) extracted from the ASTER GDEM 2 digital elevation model (30 $\mathrm{m}^{2}$ resolution; NASA \& METI 2011; ASTER GDEM is a product of the Ministry of Economy, Trade, and Industry [METI] of Japan and NASA). We calculated the distances $(\mathrm{km})$ to the nearest river or other natural water source (WaterDist; e.g. spring, wetland, ghorra). We uploaded our locations to Movebank (Dodge et al. 2013) and extracted the normalized difference vegetation index (NDVI; MODIS Land Terra Vegetation Indices) associated with each location and timestamp. Extracted NDVI values were derived using inverse distance weighted interpolation and were based on $250 \mathrm{~m}$ resolution that provides the estimate of NDVI using the highest quality image over a 16 d period. Higher NDVI values are associated with living green vegetation, while lower values are suggestive of bare ground or sparse/dead vegetation.

\subsubsection{Human factors}

Human factor covariates included the nearest (logtransformed) distance to either a human settlement or active well borehole (HumanSettle), log-transformed distance to the nearest road (RoadDist), and whether a movement step crossed a road (RoadX; $0=$ no crossing, 1 = crossing) using spatial data from the Namibian atlas (Mendelsohn et al. 2003), ConINFO (Environmental Information Service), and the Kunene regional ecological assessment (Muntifering et al. 2008). We took the log-transformed distances of $\mathrm{Hu}-$ manSettle and RoadDist because we hypothesized that the effect might only occur when zebra were located in close proximity. A veterinary exclusion fence, constructed to isolate potential disease outbreaks and protect livestock, runs the length of the study area except in a few rugged mountainous areas. Based on visualizations of zebra movements (Fig. 1), it was apparent that the fence restricts zebra range, so we calculated the number of times any actual or randomly generated movement step crossed the fence (FenceX; $0=$ no crossing, $1=$ crossing). In visually examining the steps with a fence crossing (FenceX = 1), we observed that most used steps were likely the result of 


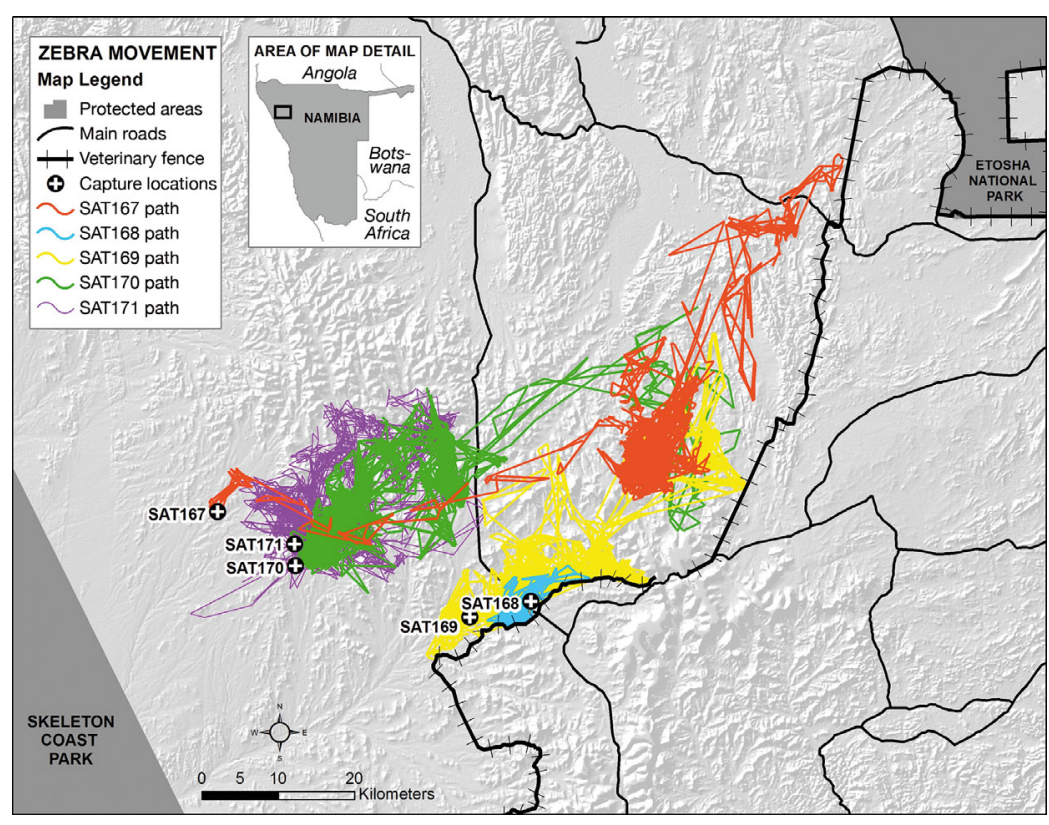

Fig. 1. Movement pathways for 5 GPS-collared Hartmann's mountain zebra located in Namibia between November 2011 and March 2013
WaterDist) along with the movement characteristics. The core model also included an interaction between NDVI and season because we expected selection for green forage to be more distinguishable during the dry season and an interaction between StepLen and DayPeriod to account for differing levels of activity throughout the day. The additional 5 models included all of the covariates from the core model specification and each human factor as an additional covariate (see Table 1 for all initial model formulations). When testing for the influence of covariates on selection, we used the covariate values associated with the terminal GPS coordinates of each step, and we used the values associated with the starting coordinates of each step when assessing the influence on movement. We did not include RoadX and RoadDist in the same model to

the straight-line movement assumption between GPS locations and the sinuosity of the fence (i.e. the zebra likely did not cross but turned direction with the curve of the fence). However, we did not change the covariate value to reflect that it was likely an artificial fence crossing (from FenceX = 1 to FenceX = 0), because we had no way to verify, and there were relatively few instances (relative to random steps where FenceX $=1$ ).

\subsection{Modelling process}

Our modelling process generally follows Prokopenko et al. (2017). We initially fitted 7 model formulations to each of our 9 zebra-year (i.e. a full year of movement data recorded per zebra) datasets individually (most zebra were collared for 2 yr; min. of 250 locations per year and season for a zebra-year to be included) using conditional logistic regression (package survival; Therneau 2018) with strata that associated the unique starting point ID of each used step with the corresponding 15 random steps that share the starting coordinates. We used zebra-year as our sampling unit because changes in seasonal forage availability among years and demographic status (with or without foal) may influence zebra movements from year to year. We created a null model that only included movement characteristics (TurnAng, StepLen) and a core model that included all temporal and natural resource covariates (NDVI, Slope, Elev, avoid issues with collinearity.

For each model formulation, we calculated an Akaike's information criterion (AIC) (Anderson 2008) value to determine which of the human factor variables (or combinations of variables) best described zebra selection and movement. The model formulation with the lowest AIC value per zebra-year model received a point. If multiple AIC scores for different model formulations were within 2 AIC points, we assigned fractions of points (e.g. if 2 models were within 2 AIC points for a zebra-year, each received 0.5). We then tallied the points by model formulation. We used the same system of accounting for the bestfitting model within each zebra-year model as Prokopenko et al. (2017) as a means of highlighting which human factors explained the most additional (i.e. in addition to the core model covariates) deviance without reporting a large number of AIC values that contain relative estimates of the deviance explained for each zebra-year. Estimated beta coefficients from our models are too narrow because they treat strata from each zebra-year model as independent. To make population-level inference, we bootstrapped the coefficient estimates from our individual zebra-year models using the same process for bootstrapping as described in Section 2.1.2 but weighted the bootstrap based on individual zebra ID. We also report the percentage of zebra-year models with the same coefficient directionality of the reported bootstrapped population sample mean. 
Table 1. Summary of model covariates and associated ranking. For each zebra-year, we fit all 7 model formulations. We considered the null model to only include step length and turning angle. Our core model (model no. 6) included all natural habitat and geographic covariates. When considering human factor covariates, we added each to the core model formulation. The logtransformed value of the covariates StepLen, HumanSettle, and RoadDist and the cosine of TurnAng were used in the model. AIC: Akaike's information criterion; NDVI: normalized difference vegetation index

\begin{tabular}{|c|c|c|c|}
\hline $\begin{array}{l}\text { Model } \\
\text { no. }\end{array}$ & Model description & Covariates & $\begin{array}{l}\text { AIC tally } \\
\text { ra-years) }\end{array}$ \\
\hline 1 & $\begin{array}{l}\text { Influence of road crossings and distance to human } \\
\text { activity on zebra movement and selection }\end{array}$ & $\begin{array}{l}\text { Core + RoadX + RoadX } \times \text { StepLen + HumanSettle } \\
\text { (end pt.) + HumanSettle (start pt.) } \times \text { StepLen }\end{array}$ & 4.5 \\
\hline 2 & $\begin{array}{l}\text { Influence of road crossings on zebra movement } \\
\text { and selection }\end{array}$ & Core + RoadX + RoadX $\times$ StepLen & 2.5 \\
\hline 3 & $\begin{array}{l}\text { Influence of distance to roadways and distance to } \\
\text { human activity on zebra movement and selection }\end{array}$ & $\begin{array}{l}\text { Core + RoadDist (end pt.) + RoadDist } \\
\text { (start pt.) } \times \operatorname{lnStepLen~}+\text { HumanSettle (end pt.) } \\
+ \text { HumanSettle (start pt.) } \times \text { StepLen }\end{array}$ & 1.5 \\
\hline 4 & $\begin{array}{l}\text { Influence of distance to roadways on zebra } \\
\text { movement and selection }\end{array}$ & $\begin{array}{l}\text { Core + RoadDist (end pt.) + RoadDist } \\
\text { (start pt.)×StepLen }\end{array}$ & 0.5 \\
\hline 5 & $\begin{array}{l}\text { Influence of distance to human activity on zebra } \\
\text { movement and selection }\end{array}$ & $\begin{array}{l}\text { Core + HumanSettle (end pt.) + HumanSettle } \\
\text { (start pt.) } \times \text { StepLen }\end{array}$ & 0 \\
\hline 6 & $\begin{array}{l}\text { Core model; movement characteristics, temporal, } \\
\text { terrain, and vegetation covariates }\end{array}$ & $\begin{array}{l}\text { Core (NDVI + NDVI:Season + Slope + Elev } \\
\text { + WaterDist + TurnAng + StepLen } \\
\text { + StepLen } \times \text { DayPeriod) }\end{array}$ & 0 \\
\hline 7 & Influence of movement covariates & Null (StepLen + TurnAng) & 0 \\
\hline
\end{tabular}

\subsection{Post hoc analyses}

Because only 4 zebra-years had any used or random steps with fence crossings, we could not include FenceX in our initial model comparisons using all zebra-year models. However, we believed the veterinary fence may strongly influence the behavior of zebra living near it. Thus, we tested 2 additional models after examining our initial model results. We used the most highly supported model formulation (i.e. with the greatest point tally) and then included the covariate FenceX and the interaction for FenceX $x$ StepLen to examine how the fence may influence zebra movement.

We also found the weak response of zebra to human settlements somewhat surprising, so we used our top model formulation and included an interaction between HumanSettle and season. We hypothesized that zebra may show differing levels of tolerance for proximity to human settlements based on the season because of differences in resources between the wet and dry seasons.

\section{RESULTS}

A total of $6 \mathrm{HMZ}$ were collared and their daily movement monitored between November 2011 and March 2013 (Fig. 1). Zebra average daily movement rates were estimated to be around 5.4 $\mathrm{km} \mathrm{d}^{-1}$ based on straight-line movements between
GPS locations $(\bar{x}[95 \% \mathrm{CI}]=5.39[4.79,5.98] \mathrm{km}$ $\mathrm{d}^{-1}$ ). Relative to the dry season, on average zebra moved greater distances each day during the rainy season (rain: $\bar{X}=5.66[4.96,5.93]$; dry: $\bar{X}=5.14$ $[4.21,6.31])$. Plots of net squared displacement indicated that for the 4 zebra with data throughout both seasons, there was a clear shift in space use between the dry and rainy seasons (see Fig. 2 for an example). During the rainy season, zebra had larger home ranges relative to the dry season based on 95\% KDEs (rain: $\bar{X}=681.2$ [287.9, 946.1]; dry: $\left.\bar{x}=255.8[74.1,419.5] \mathrm{km}^{2}\right)$ and $95 \%$ minimum convex polygons (rain: $\bar{x}=559.9[245.5$, 885.6]; dry: $\bar{x}=223.1$ [73.6-347.1] $\mathrm{km}^{2}$ ). Zebra often shifted their home ranges between seasons (\% overlap of individual's dry season 95\% KDE home range by rainy season home range: $\bar{x}=24.8$ $[6.3,74.8]$; \% rainy season home range covered by dry season home range: $\bar{x}=13.5[6.0,30.0])$, but there was considerable variability in home range overlap among different individuals (rain: $\bar{x}=11.6$ range $=2.0-22.9 \%$ of $95 \% \mathrm{KDE}$ rainy season estimates; dry: $\bar{x}=6.3 \%$ range $=0-15 \%$ of $95 \% \mathrm{KDE}$ dry season estimates). Within home ranges, zebra were located closer to natural water sources during the dry season $(\bar{x}=1.76[1.07,2.13] \mathrm{km})$, relative to the rainy season $(\bar{x}=2.73[1.72,4.15]$ $\mathrm{km})$. Zebra utilized an average elevational gradient of around $600 \mathrm{~m}$ within their home ranges $(\bar{x} \mathrm{~min}$. elevation per zebra $=788[686,867] \mathrm{m} ; \bar{X}$ max. elevation per zebra $=1374$ [1241-1507] $\mathrm{m}$ ). 


\subsection{Model ranking}

The top model included covariates that reflect the influence of road crossings and distance to human activity on zebra movement and selection (Table 1). Models including the influence of road crossings were included in the top models for 7 of 9 zebrayears. Coefficient values from the covariates in the core and the top model were similar, so all reporting of results for the core covariates were taken from the top model.

\subsection{Core covariates}

\subsubsection{Core model: resource selection}

Zebra selected for areas with higher NDVI values (NDVI: $\bar{x}[95 \% \mathrm{CI}]=$

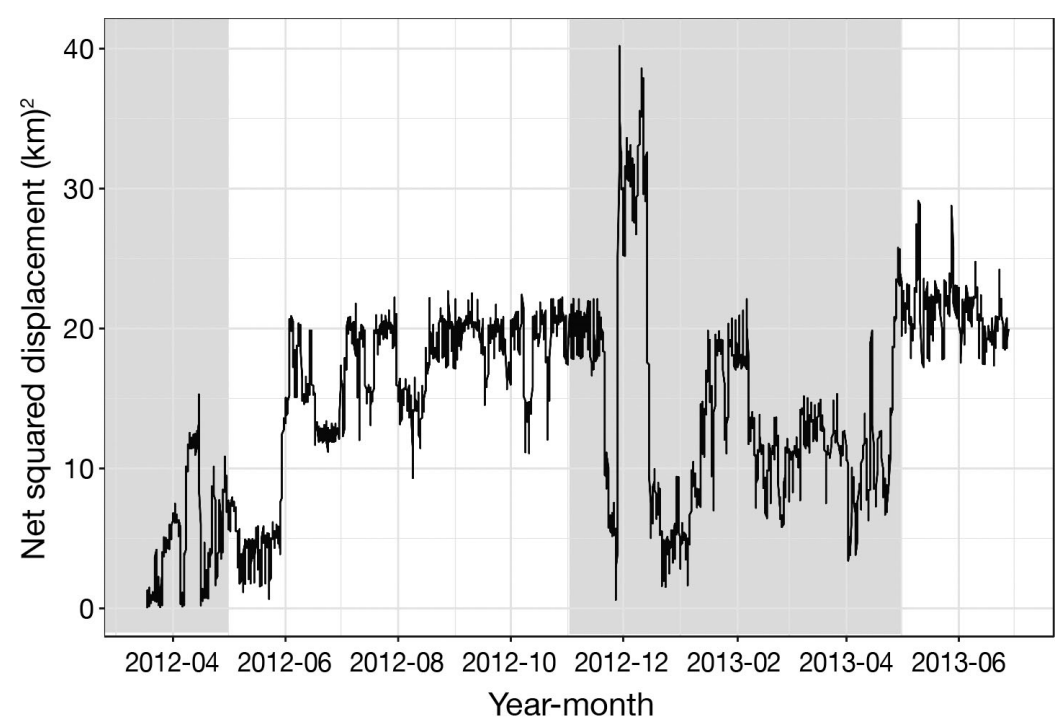

Fig. 2. Net squared displacement of a GPS-collared Hartmann's mountain zebra (individual SAT170) in Namibia from April 2012 to June 2013. The gray shaded areas represent the rainy season (November-April). We took the square root of the raw net squared displacement for ease of interpretation
$10.54[4.76,18.58] ; 88.9 \%$ of models) based on bootstrapped population means and $95 \%$ confidence intervals, although the effect was far weaker during the rainy season, when vegetation is more abundant (NDVI $\times$ Season [rain]: $\bar{x}=-4.70[-13.68,0.003] ; 75 \%$ of models). Zebra avoided areas further from natural water sources (WaterDist: $\bar{x}=-0.26[-0.35,-0.092]$; $89 \%$ of models) and areas with higher elevations (Elev: $\bar{x}=-1.62[-4.48,-0.72] ; 89 \%$ of models) but were not influenced by slope (Slope: $\bar{x}=0.00[-0.014$, 0.0039]).

\subsubsection{Core model: movement}

Overall, zebra did not consistently show directional persistence in their movements (TurnAng: $\bar{x}=-0.023$ $[-0.028,0.047])$. Zebra movement rates were greatest during the crepuscular times of day relative to daylight (StepLen $\times$ DayPeriod[day]: $\bar{X}=-0.11[-0.25$, $-0.0009]_{;} 67 \%$ of models) and especially when compared to nighttime periods (StepLen $\times$ DayPeriod [night]: $\bar{x}=-0.46[-0.54,-0.37] ; 100 \%$ of models).

\subsection{Human factor covariates}

\subsubsection{Human factor model: resource selection}

Seven of 9 zebra-year models indicated selection for areas further away from human activity (Fig. 3A), but the bootstrapped population 95\% confidence interval overlapped zero (HumanSettle: $\bar{x}=0.38$ $[-0.28,0.56])$. Zebra commonly crossed roads ( $\bar{x} \%$ of total movement steps with a crossing $=19.1 \%[13.4$, $24.5 \%$ ] by zebra-year) but less so than expectedindicating avoidance (RoadX: $\bar{x}=-0.65[-0.92$, $-0.43] ; 100 \%$ of models). Though the model formulation including distance to the nearest road (RoadDist) was only included in $22 \%$ of zebra-year top models (Table 1), coefficient values indicate a consistent selection for areas closer to roadways (RoadDist: $\bar{x}=$ $-0.041[-0.13,-0.027] ; 89 \%$ of models; Fig. 3A).

\subsubsection{Human factor model: movement}

Zebra movements were not consistently influenced by proximity to areas of high human activity (HumanSettle $\times$ StepLen: $\bar{x}=-0.16[-0.28,0.084]$; Fig. 3B). Zebra movement rates increased when crossing roads (RoadX $\times$ StepLen: $\bar{X}=0.63$ [0.30, 0.73]; $100 \%$ of models) and when closer to roadways (RoadDist $\times$ StepLen: $\bar{X}=-0.063[-0.14,-0.043] ; 100 \%$ of models).

\subsection{Post hoc analysis using top model}

\subsubsection{Influence of fences}

The veterinary fence influenced the movements of the individual zebra that were located near it. The 


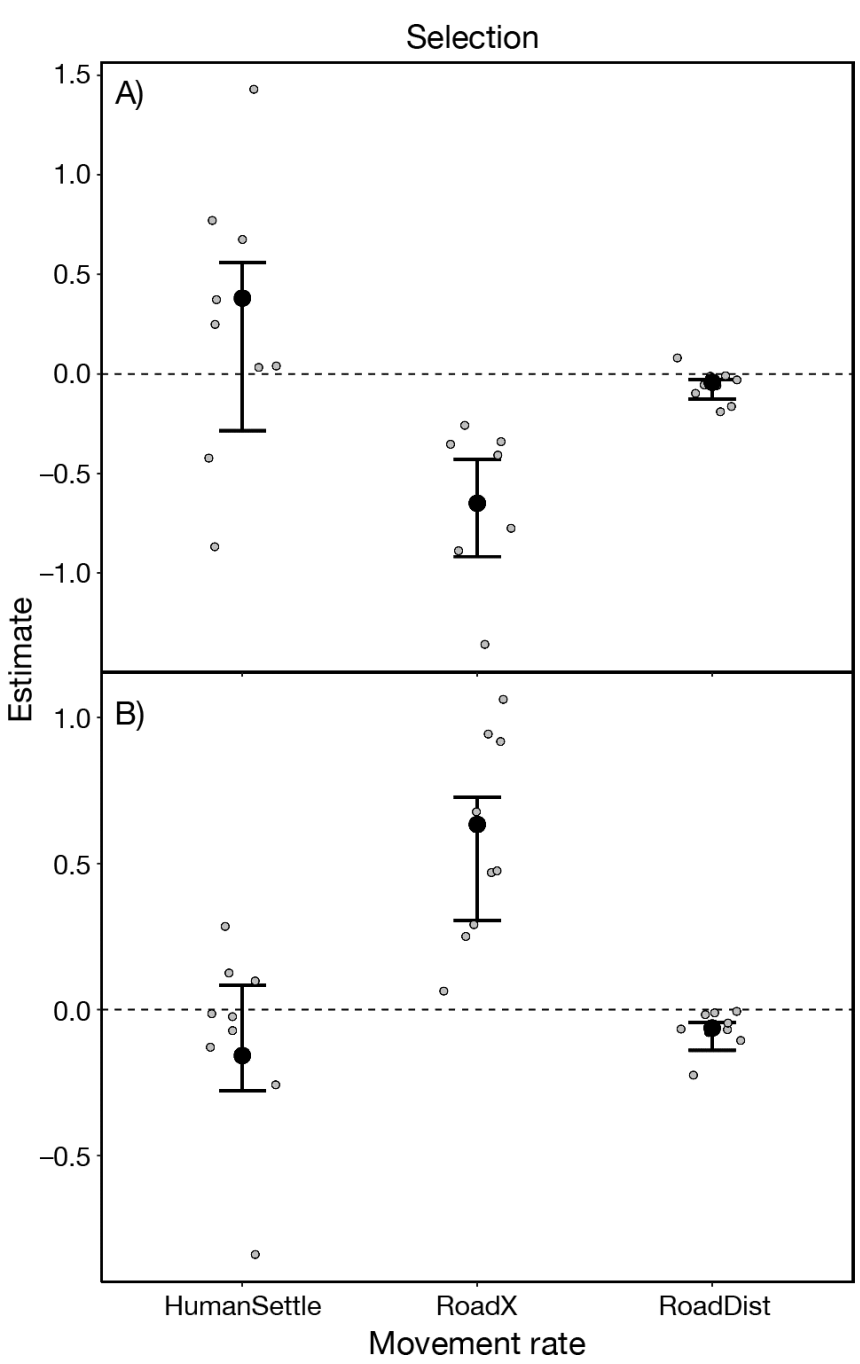

Fig. 3. Individual coefficient estimates and bootstrapped population mean and $95 \%$ confidence intervals from integrated step selection function models of GPS-collared Hartmann's mountain zebra in Namibia from 2010 to 2013. The influence of 3 human factors on the landscape are shown here for the effect on (A) zebra resource selection and (B) zebra movement (interaction between the covariate and logtransformed step length): (1) HumanSettle = distance to the nearest village or man-made water source, (2) RoadX = whether the movement step intersected with a roadway, and (3) RoadDist = distance to the nearest roadway. For distancebased covariates (HumanSettle, RoadDist), the distance to a feature was based on the starting location of each movement step when considering the influence of movement (B), and the distance between the terminal location of each movement step was used for estimating distances when considering selection $(\mathrm{A})$

top models from 3 of 4 zebra-year models that included FenceX and FenceX $\times$ StepLen had large reductions in their AIC scores (range of AIC reduction from top model of each zebra-year model: 71-154), suggesting very strong support for the inclusion of FenceX and FenceX $\times$ StepLen. Fence crossings dur- ing these 4 zebra-years occurred rarely $(0.65 \%$; [95\% CI: 0.19, 2.69\%] of movement steps), when compared to the random movement steps generated for the iSSF ( $4.85 \%$; [95\% CI: 1.31, $7.91 \%$ ]), resulting in avoidance of fence crossings for all zebra-years (FenceX $\hat{\beta}$ for each zebra-year $=-12.64,-3.70,-3.64$, -1.72 ). Fence crossings did not consistently influence movement rates in these 4 zebra-year models (StepLen $\times$ FenceX $\hat{\beta}$ for each zebra-year $=-0.35$, $-0.27,0.85,1.04)$.

\subsubsection{Seasonal influence of human activity}

Including an interaction between season and distance to human activity reduced AIC values by $>2$ in $25 \%$ of models relative to the top model without the interaction. In this model, zebra again selected for areas further from human activity (HumanSettle: $\bar{x}=$ $0.61[-0.14,1.13]$; positive in $63 \%$ of models) but less so during the rainy season (HumanSettle $\times$ Season [rain]: $\bar{X}=-0.50[-0.95,0.29]$; negative in $75 \%$ of models). Again, zebra movement rates were not influenced by the distance to human activity $(\bar{x}=$ $-0.017[-0.067,0.13])$.

\section{DISCUSSION}

Ensuring conservation action is effective in the Anthropocene era (Caro et al. 2012, Ripple et al. 2015) will benefit from evidence-based studies that seek to better understand how wild animals, particularly wide-ranging species such as free-ranging equids, behave in human-dominated landscapes and respond to a changing climate, conditions which are transforming wildlife habitat around the world (Sloat et al. 2018). Our analysis detailed how HMZ movements and resource use are closely tied to the seasonality of NDVI at a fine scale, while demonstrating how human components to the landscape may alter their abilities to reach resources or change their movement patterns when seeking them out. Prior to this analysis, very few studies have provided any detailed documentation on the ranging behavior of the HMZ. Here, we provide one of the first quantitative studies on home range, resource selection, and movement as well as the effects of human development on free-ranging $\mathrm{HMZ}$ in Namibia.

Our findings provide some important updated basic knowledge on ranging behavior that could be compared with other zebra and equid species. Freeranging $\mathrm{HMZ}$ were observed to cover approximately 
$5 \mathrm{~km} \mathrm{~d}^{-1}$ or $1825 \mathrm{~km} \mathrm{yr}^{-1}$, with negligible differences between seasons. However, estimated home range size differed substantially between seasons and averaged between 681 and $256 \mathrm{~km}^{2}$ in the wet and dry season, respectively, with a maximum of nearly $950 \mathrm{~km}^{2}$. This is more or less similar to other plains zebra studied in large open landscapes such as the Kruger National Park in South Africa (Smuts 1975), Serengeti (Klingel 1969), and Botswana (BartlamBrooks et al. 2013, Naidoo et al. 2014) and is typical of equids ranging across arid, resource-limiting open landscapes such as Przewalski horses in the Gobi desert landscapes of both Mongolia (Kaczensky et al. 2008) and China (Chen 2008). However, it is surprisingly less than Grevy's zebra, which have been found to range over $10000 \mathrm{~km}^{2}$ in parts of Kenya (Rubenstein et al. 2016). This could be due, in part, to our sampling window occurring during and just following an exceptionally wet period (2010-2011) in northwestern Namibia with rainfall figures reaching 4 to 5 times above average. Although wet season ranges are often longer than dry, an extended wet period with high-quality forage easily available may also reduce home range sizes temporarily. Some HMZ individuals were also observed to have very little home range overlap between dry and wet seasons, but others exhibited high degrees of overlap. This suggests that some HMZ groups may indeed have smaller seasonal home ranges, like their close relatives, Cape mountain zebra, in South Africa (Penzhorn 1982, 1988), but ranges may vary between groups (Owen-Smith 2013) or only a portion of the population is migratory, as documented for other zebra populations (Georgiadis et al. 2003). However, our reported home range sizes here are significantly larger than the $6-20 \mathrm{~km}^{2}$ ranges previously reported by Joubert (1972) for HMZ in western Etosha National Park, Namibia.

Our results using an iSSF modelling technique mostly confirmed what we hypothesized about HMZ resource selection and effects of human-induced disturbance. Many studies on equid species, and zebra species specifically across Africa, have reported their ranging behavior to be heavily influenced by rainfall and associated high-quality resource availability (Young et al. 2005, Schoenecker et al. 2016). Using NDVI as a proxy for vegetation productivity, HMZ demonstrated strong selection towards areas of high primary productivity, especially during the dry season, confirming our first hypothesis that they would seek out areas with high-quality grazing. This is consistent with previous research that indicates mountain zebra need consistent access to quality and con- stant grazing (Penzhorn \& Novellie 1991) and corroborates with other regional studies of other zebra habitat selection and ranging behavior (BartlamBrooks et al. 2013, Naidoo et al. 2014).

In addition to selecting areas of high NDVI, HMZ were found to select areas exceptionally close to permanent water and lower elevation. Monitored zebra rarely moved beyond $4 \mathrm{~km}$ from water sources, averaging less than $2 \mathrm{~km}$ in the dry season, confirming our second hypothesis that HMZ would not be located in areas far from a permanent water source. These results further confirm their water dependency (Joubert 1972) and are similar to those found for Grevy's zebra, which rarely range beyond $10 \mathrm{~km}$ from permanent water (Hostens 2009). This finding emphasizes the importance of ensuring zebra have sufficient access to permanent water to maintain functionally connected landscapes. Even relatively small increases in NDVI variability or reductions in access to high-NDVI forage, from either direct human alterations to the landscape or climatic change, may negatively impact reproduction (Stoner et al. 2016).

Most notably, our iSSF analysis demonstrates the negative effect of human activity on resource selection and the negative impact of roads on HMZ movement. Our results indicate that zebra select areas further from human settlement. This is not surprising, considering nearly every settlement in the area is dominated by livestock, creating competition for grazing closer to settlements. However, the effect of human settlement on movement was not substantial. This would likely be due to the relatively small distance threshold of human impact from settlements. For example, previous social surveys across 136 settlements within and surrounding our study area documented that livestock rarely moved beyond 4 to $6 \mathrm{~km}$ from their kraals at each settlement (Muntifering et al. 2008). Thus, any direct competition from livestock, especially cattle, would be the same at any distance beyond $6 \mathrm{~km}$ from settlements. Given the very low human population density in the region at less than 1 $\mathrm{km}^{-2}$ (Steytler 2014), it is not surprising that if zebra are already avoiding human settlements, their finerscale movement decisions would not be influenced much by human activity. The strong avoidance of human activity areas has been well documented for other zebra in Kenya (Young et al. 2005) and for Grevy's (Hostens 2009) and other equid species, especially kiang or Tibetan wild ass (Sharma 2004), whose ranges are heavily restricted by livestock distribution. Even other related species within the perissodactyl order (odd-toed ungulates), such as freeranging black rhino populations in the Masai Mara 
and northwestern Namibia, have been found to show strong avoidance towards humans and livestock (Walpole et al. 2003, Muntifering et al. 2008).

HMZ also slightly selected for areas closer to roads but increased their movement rates substantially in close proximity to roads and when crossing them. This has been found elsewhere for other migrating ungulates such as elk (Prokopenko et al. 2017) and moose (Berger 2007). Although we did not test the related effects on demographic rates and population performance, these results suggest that areas near roads may have resources sought out by HMZ but that crossing these foreign linear landscape features alters the movements of this wide-ranging species as they attempt to reach critical resources.

In addition to roads, 3 of our collared zebra clearly demonstrated the negative barrier effects of fences by spending significant time moving alongside the veterinary fence which bisects Namibia, but not crossing it. Although inference is somewhat limited by the small sample size, this suggests critical resources were likely being sought out along or on the other side of the fence, but the zebra failed to find a way to cross although some locations appeared to cross the fence by a few meters due to GPS collar error. The same fence had devastating effects on HMZ in the 1980-1982 drought in the area where hundreds of emaciated zebra carcasses were found lying along the fenceline (Gosling et al. 2018). Research in neighboring Botswana recently discovered that following the removal of the same veterinary fence, over 15000 plains zebra began migrating to what has been suggested as ancient migratory areas after 50 yr (Bartlam-Brooks et al. 2013). We acknowledge that the intervals between time steps (i.e. $4 \mathrm{~h}$ ) somewhat limit inferences associated with our movement results and thus suggest some caution in interpretation.

Last, our analysis provides useful insights towards informing human development planning for the landscape as well as designing future managementoriented research to fill key knowledge gaps. Two key trends emerging in northwestern Namibia that may significantly affect HMZ conservation are a relatively small but persistent positive growth in the human population and the tourism industry. These trends offer opportunities for conservation, especially the tourism industry, yet they also create challenges for management. The expanding human populations consistently seek areas to graze their livestock and demand infrastructure improvements such as roads to enhance mobility and accessibility. Tourism development also requires similar infrastructure expan- sion with ever-expanding lodges to cater to the increasing numbers of tourists, exerting greater pressure on already low water levels. Under the most recent climate projections, the area is likely to experience more frequent and intense drought conditions. As drought conditions worsen, farmers will become more desperate to find grazing areas for their livestock, and the negative impacts of tourism development may become more relevant, likely increasing competition with persisting HMZ. The evidence compiled here on the tendency of HMZ to avoid human development and activity extenuates the importance of ensuring that future development planning takes into account impacts on wide-ranging vulnerable and valuable species such as HMZ and works to minimize impacts.

Acknowledgements. We thank Namibia's Ministry of Environment and Tourism as well as Palmwag and Etendeka concessionaires for permission to conduct this research. We thank both Dr. Mark Jago and Dr. Axel Hartmann for leading the capture and collaring. We are grateful for funding received from The Nature Conservancy for the GPS collars and Disney's Animal Kingdom, Minnesota Zoo's Ulysses S. Seal Conservation Grant Program and Volunteer Activity Program, Wilderness Wildlife Trust, Oregon Zoo's Future for Wildlife Conservation Fund, Roger Williams Park Zoo's Sophie Danforth Conservation Biology Fund, NEW Zoological Society's Conservation Fund, and the B. Bryan Preserve for logistical support.

\section{LITERATURE CITED}

Anderson DR (2008) Model based inference in the life sciences. Springer, New York, NY

Avgar T, Potts JR, Lewis MA, Boyce MS (2016) Integrated step selection analysis: bridging the gap between resource selection and animal movement. Methods Ecol Evol 7:619-630

Bartlam-Brooks HLA, Beck PSA, Bohrer G, Harris S (2013) In search of greener pastures: using satellite images to predict the effects of environmental change on zebra migration. J Geophys Res Biogeosci 118:1427-1437

*Benhamou S (2006) Detecting an orientation component in animal paths when the preferred direction is individualdependent. Ecology 87:518-528

Berger J (2007) Fear, human shields and the redistribution of prey and predators in protected areas. Biol Lett 3: 620-623

* Bivand R, Lewin-Koh N (2017) Maptools: tools for reading and handling spatial objects. R package version 0.9-2. https://CRAN.R-project.org/package=maptools

*Boyce MS (2006) Scale for resource selection functions. Divers Distrib 12:269-276

* Calenge C (2006) The package 'adehabitat' for the R software: a tool for the analysis of space and habitat use by animals. Ecol Modell 197:516-519

* Canty A, Ripley B (2017) Bootstrap R (S-Plus) functions. R package version 1.3-20. https:/CRAN.R-project.org/ package $=$ boot 
Caro TIM, Darwin J, Forrester T, Ledoux-Bloom C, Wells C (2012) Conservation in the Anthropocene. Conserv Biol 26:185-188

Chen J (2008) Utilization of food, water and space by released Przewalski horse with reference to survival strategies analysis. PhD thesis, Beijing Forestry University, Beijing

Dodge S, Bohrer G, Weinzierl R, Davidson SC and others (2013) The environmental-data automated track annotation (Env-DATA) system: linking animal tracks with environmental data. Mov Ecol 1:1-14

Georgiadis N, Hack M, Turpin K (2003) The influence of rainfall on zebra population dynamics: implications for management. J Appl Ecol 40:125-136

Gosling LM, Muntifering JR, Kolberg H, Uiseb K, King SRB (2018) Equus zebra ssp. hartmannae. The IUCN Red List of Threatened Species 2018. IUCN, Gland

Hostens E (2009) Modelling the migration of Grevy's zebra in function of habitat type using remote sensing. University of Gent, Gent

IUCN (2017) The IUCN Red List of Threatened Species. Version 2017-3. IUCN, Gland

Jacobson P, Jacobson KMS (1995) Ephemeral rivers and their catchments: sustaining people and development in western Namibia. Desert Research Foundation of Namibia, Windhoek

Joubert E (1972) The social organization and associated behaviour in the Hartmann zebra (Equus zebra hartmannae). Madoqua 6:17-55

Kaczensky P, Ganbaatar O, Von Wehrden H, Walzer C (2008) Resource selection by sympatric wild equids in the Mongolian Gobi. J Appl Ecol 45:1762-1769

Klingel H (1969) The social organisation and population ecology of the plains zebra (Equus quagga). Zool Africana 4:249-263

Krecek NJP, Horak IG, Malan FS (1994) Helminth parasites of Cape mountain zebras from Cape Province, South Africa. J Wildl Dis 30:277-280

Lea J, Ih G, Hrabar H, Barry TJ, Shultz S (2016) Recognition and management of ecological refugees: a case study of the Cape mountain zebra. Biol Conserv 203: 207-215

Lea JMD, Walker SL, Kerley GIH, Jackson J, Matevich SC, Shultz S (2018) Non-invasive physiological markers demonstrate link between habitat quality, adult sex ratio and poor population growth rate in a vulnerable species, the Cape mountain zebra. Funct Ecol 32:300-312

Leggett K, Fennessy J, Schneider S (2004) A study of animal movement in the Hoanib River catchment, northwestern Namibia. Afr Zool 39:1-11

Lloyd PH, Rasa OAE (1989) Status, reproductive success and fitness in Cape mountain zebra (Equus zebra zebra). Behav Ecol Sociobiol 25:411-420

Maure G, Pinto I, Ndebele-Murisa M, Muthige M and others (2018) The southern African climate under $1.5^{\circ} \mathrm{C}$ and $2{ }^{\circ} \mathrm{C}$ of global warming as simulated by CORDEX regional climate models. Environ Res Lett 13

Mendelsohn J, Jarvis A, Roberts C, Robertson T (2003) Atlas of Namibia: a portrait of the land and its people. David Philip Publishers, Cape Town

Moehlman PD, King SRB, Kebede F (2016) Status and conservation of threatened equids. In: Ransom J, Kaczensky $\mathrm{P}$ (eds) Ecology, management and conservation of wild equids. John Hopkins University, Baltimore, MD, p 167-186
Muntifering JR, Lockhart CJ, Tingey R, Griggs J, Heinemeyer K, Lalley J, Sizemore D (2008) The Kunene regional ecological assessment. Round River Conservation Studies, Salt Lake City, UT

NACSO (Namibia Association of CBNRM Support Organisations) (ed) (2014) The state of community conservation in Namibia: a review of communal conservancies, community forests and other CBNRM initiatives (2013 annual report). NACSO, Windhoek

Naidoo R, Chase MJ, Beytell P, Du Preez P, Landen K, Stuart-Hill G, Taylor R (2014) A newly discovered wildlife migration in Namibia and Botswana is the longest in Africa. Oryx 50:1-9

NASA (National Aeronautics and Space Administration), METI (Ministry of Economy, Trade, and Industry) (2011) ASTGTM: ASTER Global Digital Elevation Model. NASA EOSDIS Land Processes DAAC, USGS Earth Resources Observation and Science (EROS) Center, Sioux Falls, SD. https://lpdaac.usgs.gov (accessed December 14, 2017)

Northrup JM, Hooten MB, Anderson CR, Wittemyer G (2013) Practical guidance on characterizing availability in resource selection functions under a use-availability design. Ecology 94:1456-1463

Novellie P, Birss C, Cowell C, Kerley GIH and others (2017) Adaptive governance of Cape mountain zebra, Can it work? Afr J Wildl Res 47:79-91

${ }^{\prime}$ 'Brien TG, Kinnaird MF, Ekwanga S, Wilmers C and others (2018) Resolving a conservation dilemma: vulnerable lions eating endangered zebras. PLOS ONE 13:e0201983

* Owen-Smith N (2013) Daily movement responses by African savanna ungulates as an indicator of seasonal and annual food stress. Wildl Res 40:232-240

* Parker GE, Davidson Z, Low B, Lalampaa PR, Sundaresan SR, Fischer M (2017) Can pastoral communities offer solutions for conserving the Endangered Grevy's zebra (Equus grevyi) at the periphery of its range. Oryx 51: $517-526$

Penzhorn BLI (1982) Home range sizes of Cape mountain zebras in the Mountain Zebra National Park. Koedoe 25: 103-108

* Penzhorn BLI (1988) Equus zebra. Mamm Species 314:1-7

Penzhorn BLI, Novellie PA (1991) Some behavioural traits of Cape mountain zebras (Equus zebra zebra) and their implications for the management of a small conservation area. Appl Anim Behav Sci 29:293-299

* Poor EE, Loucks C, Jakes A, Urban DL (2012) Comparing habitat suitability and connectivity modeling methods for conserving pronghorn migrations. PLOS ONE 7:e49390

*Pokopenko CM, Boyce MS, Avgar T (2017) Characterizing wildlife behavioural responses to roads using integrated step selection analysis. J Appl Ecol 54:470-479

* Purdon A, Mole MA, Chase MJ, van Aarde RJ (2018) Partial migration in savanna elephant populations distributed across southern Africa. Sci Rep 8:11331

Nevelopment Core Team (2015) R: a language and environment for statistical computing. R Foundation for Statistical Computing, Vienna. https://www.r-project.org/

Rasa OA, Lloyd PH (1994) Incest avoidance and attainment of dominance by females in a Cape mountain zebra population. Behaviour 128:3-4

Ripple WJ, Newsome TM, Wolf C, Dirzo R and others (2015) Collapse of the world's largest herbivores. Sci Adv 1: e1400103

Ripple WJ, Chapron G, López-Bao JV, Durant SM and oth- 
ers (2016) Saving the world's terrestrial megafauna. Bioscience 66:807-812

Ripple WJ, Chapron G, López-Bao JV, Durant SM and others (2017) Conserving the world's megafauna and biodiversity: the fierce urgency of now. Bioscience 67:197-200

Rubenstein D, Low Mackey B, Davidson ZD, Kebede F, King SRB (2016) Equus grevyi. The IUCN Red List of Threatened Species 2016: e.T7950A89624491. http://dx.doi. org/10.2305/IUCN.UK.2016-3.RLTS.T7950A89624491.en

Schoenecker K, King S, Nordquist M, Nandintsetseg D, Cao Q (2016) Habitat and diet of equids. In: Ransom J, Kaczensky P (eds) Wild equids: ecology, management and conservation. John Hopkins University, Baltimore, MD, p 41-57

Sharma B (2004) Mapping Equus kiang (Tibetan wild ass) habitat in Surkhang, Upper Mustang, Nepal. Mt Res Dev 24:149-156

Signer J (2018) amt: animal movement tools. R package version 0.0.5.0. https://CRAN.R-project.org/package=amt

Signer J, Fieberg J, Avgar T (2019) Animal movement tools (amt): R package for managing tracking data and conducting habitat selection analyses. Ecol Evol 9:880-890

Sloat LL, Gerber JS, Samberg LH, Smith WK and others (2018) Increasing importance of precipitation variability on global livestock grazing lands. Nat Clim Chang 8:214-218

Smith RK, Marais A, Chadwick P, Lloyd PH, Hill A (2007) Monitoring and management of the endangered Cape mountain zebra Equus zebra zebra in the Western Cape, South Africa. Afr J Ecol 46:207-213

Smuts GL (1975) Home range sizes for Burchell's zebra Equus burchelli antiquorum from the Kruger National Park. Koedoe 18:139-146

Steytler J (2014) Namibia population projections. Windhoek

Stoner DC, Sexton JO, Nagol J, Bernales HH, Edwards TC Jr (2016) Ungulate reproductive parameters track satellite observations of plant phenology across latitude and

Editorial responsibility: Matt Hayward, Bangor, UK climatological regimes. PLOS ONE 11:e0148780

* Therneau TM (2018) Survival analysis. Version 2.42-6. https://cran.r-project.org/web/packages/survival/index. html

Thurfjell H, Ciuti S, Boyce MS (2014) Applications of stepselection functions in ecology and conservation. Mov Ecol 2:4

Walpole M, Karanja G, Sitati NW, Leader-Williams N (2003) In: Walpole M, Karanja G, Sitati NW, Leader-Williams N (eds) Wildlife and people: conflict and conservation in Masai Mara, Kenya International Institute for Environment and Development, London

*Wasserman TN, Cushman S, Shirk A, Landguth EL, Littell JS (2012) Simulating the effects of climate change on population connectivity of American marten (Martes americana) in the northern Rocky Mountains, USA. Landsc Ecol 27:211-225

Watson LH, Chadwick P (2007) Management of Cape mountain zebra in the Kammanassie Nature Reserve, South Africa. S Afr J Sci 37:31-39

*Watson LH, Odendaal HE, Barry TJ, Pietersen J (2005) Population viability of Cape mountain zebra in Gamka Mountain Nature Reserve, South Africa: the influence of habitat and fire. Biol Conserv 122:173-180

*Weel S, Watson LH, Weel J, Venter JA (2015) Cape mountain zebra in the Baviaanskloof Nature Reserve, South Africa: resource use reveals limitations to zebra performance in a dystrophic mountainous ecosystem. Afr J Ecol 53:428-438

* Young TP, Palmer TM, Gadd ME (2005) Competition and compensation among cattle, zebras, and elephants in a semi-arid savanna in Laikipia, Kenya. Biol Conserv 122: 351-359

Keller KA, McGarigal K, Whiteley AR (2012) Estimating landscape resistance to movement: a review. Landsc Ecol $27: 777-797$

Submitted: September 19, 2018; Accepted: January 7, 2019 Proofs received from author(s): March 7, 2019 